\title{
Transapical Aortic Valve Replacement Aided by Cardiopulmonary Bypass in a Patient with a Left Ventricular Thrombus
}

\author{
Mingyu $\mathrm{Qu}^{1}$, Li $\mathrm{Bao}^{2}$, and Sheng Jing ${ }^{3}$ \\ ${ }^{1}$ The Second Affiliated Hospital, Army Medical University (Third Military Medical \\ University) \\ ${ }^{2}$ Third Military Medical University Second Affiliated Hospital \\ ${ }^{3}$ Affiliation not available
}

July 31,2021

\begin{abstract}
Aortic stenosis is one of the most common degenerative valvular diseases in the elderly. Transapical aortic valve implantation (TAVI) is an innovative technique for high-risk patients with severe, symptomatic aortic stenosis and multiple comorbidities. However, potential obstruction to the left ventricular outflow tract, from a left ventricular thrombus, poses significant patient risk and challenge for the anesthetist. An 82-year-old man with these conditions underwent TAVI and intracardiac thrombectomy under general anesthesia, combined with cardiopulmonary bypass. We abandoned traditional surgical aortic valve replacement and thrombectomy; a fast-track cardiac anesthesia strategy was adopted. No complications were observed during recovery. Cardiac function was normal upon follow-up 1 year, post-operatively. Transapical aortic valve replacement aided by cardiopulmonary bypass, implemented under Enhanced Recovery After Surgery (ERAS) strategy, is suitable for high-risk patients under similar conditions. Strategies and equipment should be maximized for analgesia, organ protection, and circulatory homeostasis for perioperative safety and enhanced prognosis.
\end{abstract}

\section{Hosted file}

Transapical_Aortic_Valve_Replacement_Aided \selectlanguage\{ngerman\} by Card.pdf available at https://authorea.com/users/428497/articles/532326-transapical-aortic-valve-replacementaided-by-cardiopulmonary-bypass-in-a-patient-with-a-left-ventricular-thrombus 

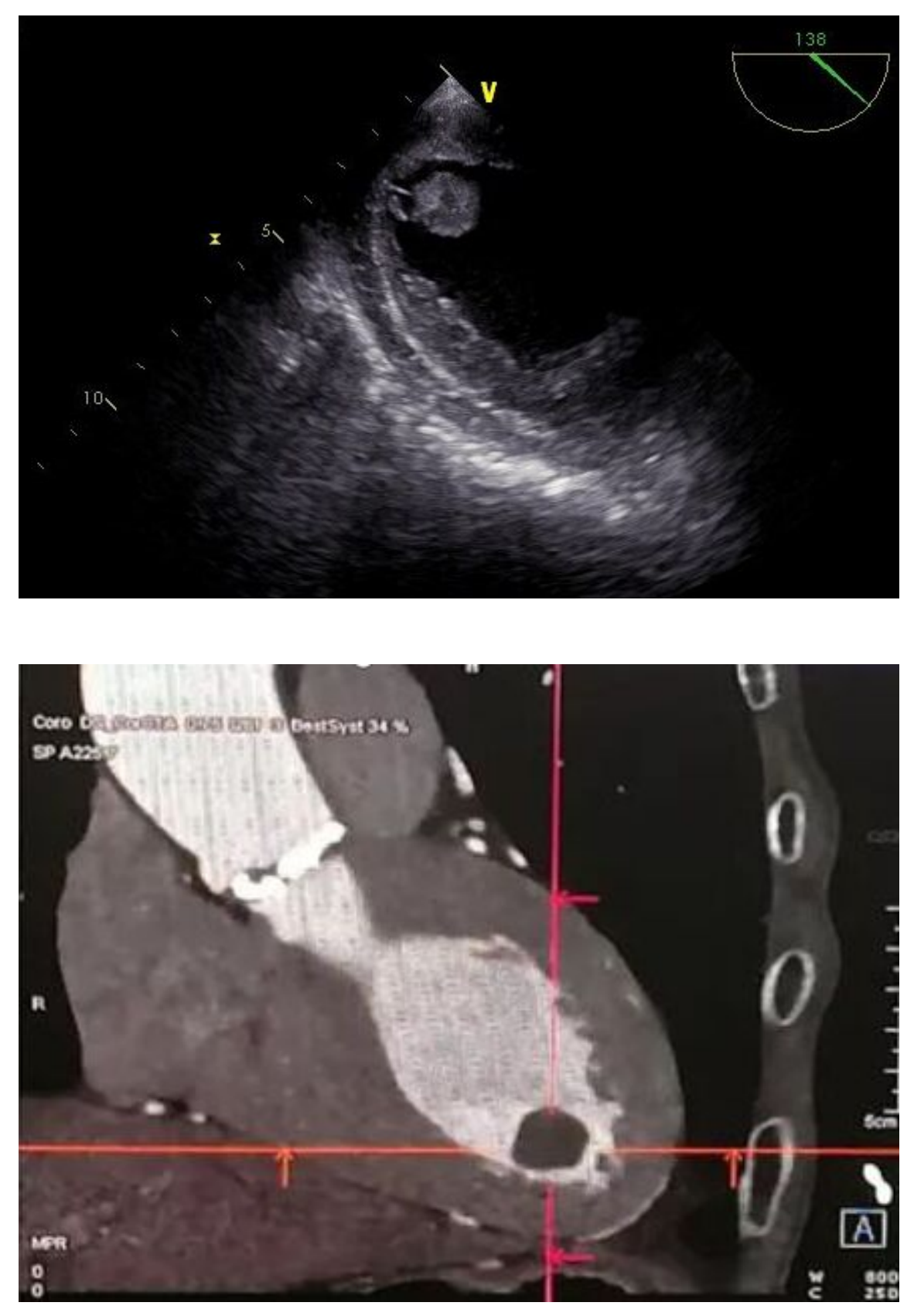


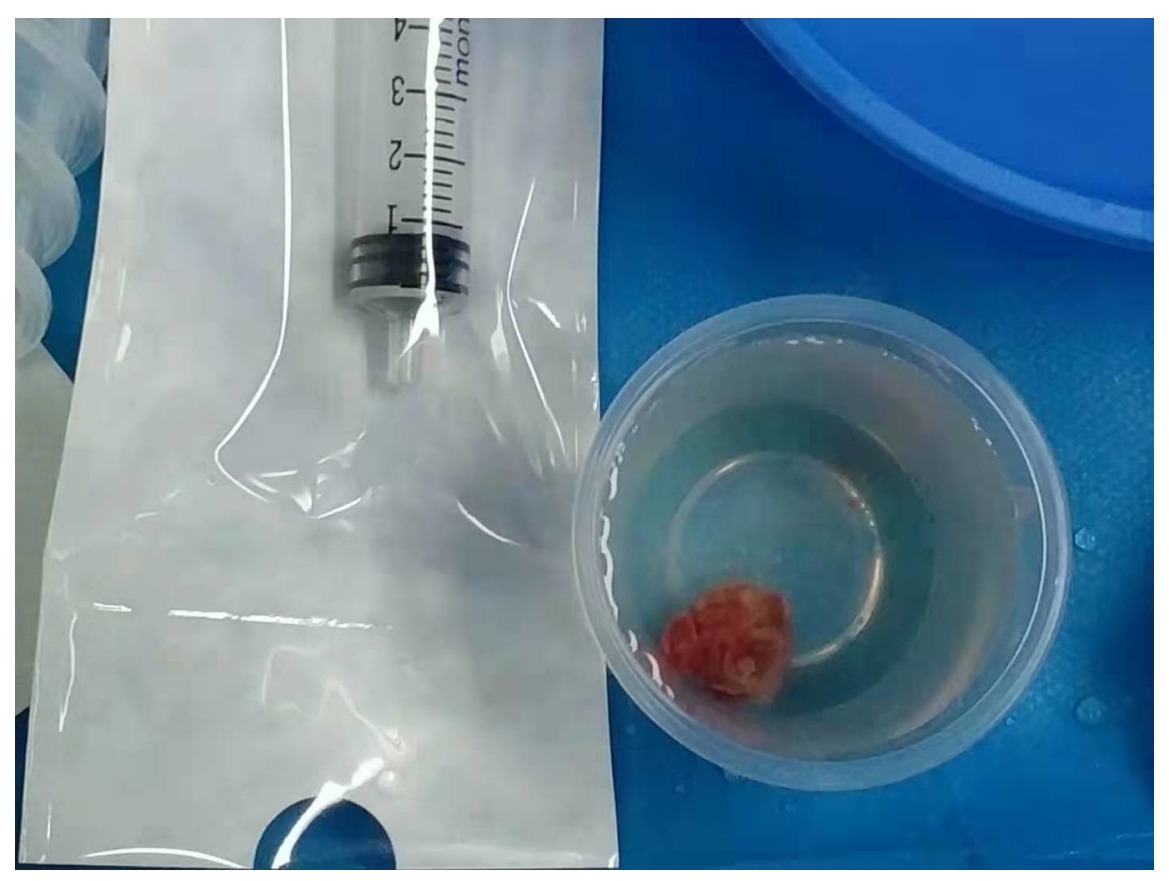

